\title{
Age and Growth of Pointhead Flounder Hippoglossoides pinetorum in Ishikari Bay, Hokkaido
}

\author{
Osamu Tominaga, ${ }^{* 1}$ Ken Inoguchi, ${ }^{* 2}$ Yasuhiro Watanabe, ${ }^{* 3}$ \\ Motohito Yamaguchi, ${ }^{* 3}$ Toshikuni Nakatani, ${ }^{* 2}$ and Toyomi Takahashi*2 \\ ${ }^{*}$ Faculty of Biotechnology, Fukui Prefectural University, Obama, Fukui 917, Japan \\ ${ }^{*}$ Faculty of Fisheries, Hokkaido University, Minato, Hakodate, Hokkaido 041, Japan \\ ${ }^{*}$ Hokkaido Fisheries Experimental Station, Hamanaka, Yoichi, Hokkaido 046, Japan \\ (Received July 24, 1995)
}

\begin{abstract}
Pointhead flounder, Hippoglossides pinetorum, taken by commercial gillnets and an experimental beam trawl net in Ishikari Bay, Hokkaido from September 1991 to July 1993 were aged using polished otoliths (saggitae). Ages were validated by the monthly change in the percentage of otolith with translucent edge and marginal increments; a single opaque and translucent zone was formed annually. The regression method and Lee (Fraser-Lee)'s method were used to estimate the back-calculated length. Growth of pointhead flounder was expressed as $\mathrm{L}_{t}=251.9\left(1-\exp ^{-0.261(t-0.142)}\right)$ for males and $\mathrm{L}_{\mathrm{t}}$ $=315.1\left(1-\exp ^{-0.219(t-0.200)}\right)$ for females using back-calculated lengths by the regression method and $L_{t}$ $=251.6\left(1-\exp ^{-0.263(t-0.142)}\right)$ for males and $\mathrm{L}_{\mathrm{t}}=333.0\left(1-\exp ^{-0.204(\mathrm{t}-0.186)}\right)$ for females using back-calculated lengths by Lee's method, where $L_{t}$ is the standard length $(\mathrm{mm})$ at estimated age $t$. Small differences in the theoretical lengths of older female fish were found between the two methods. However, the theoretical standard lengths predicted by the two methods were very similar at most estimated ages and indicated the approximate actual length at each age.
\end{abstract}

Key words: Hippoglossoides pinetorum, age, growth, otolith

Pointhead flounder Hippoglossoides pinetorum is an important commercial fish off the coastal waters of Hokkaido and south-western Honshu Island. In the coastal waters of Hokkaido, the annual catch of this species by offshore fisheries was over 10,000 metric ton in 1972, but thereafter gradually decreased and has been less than 2,000 metric ton for the last ten years. In response to this decrease of harvested resource, stock management plans are required. Although there are some studies on the migratory and distributional patterns of adults, ${ }^{1-4)}$ feeding habits ${ }^{5)}$ and the distribution of planktonic larvae $e^{6}$ in the coastal waters of Hokkaido, there has been no accurate aging study, which is the basis for fisheries management decisions.

The objective of the present study was to validate the aging method using otoliths of pointhead flounder from Ishikari Bay, one of the major fishing grounds for this species.

\section{Materials and Methods}

The samples used in this study were caught with commercial bottom gill nets in Ishikari Bay, Hokkaido (Fig. 1) from March to December, 1992 (Table 1). Fish were also obtained with an experimental beam trawl net (codend mesh aperture, $2.5 \mathrm{~mm}$ ) aboard the R/V Oyashio-maru of Hokkaido Fisheries Experimental Station in Ishikari Bay from June 1991 to July, 1993 (Table 1). All specimens collected were sexed, measured to the nearest millimeter in standard length (SL), and weighed to the nearest $0.1 \mathrm{~g}$. The largest otoliths, the saggitae, were removed and preserved in $70 \%$ ethanol for later analysis.

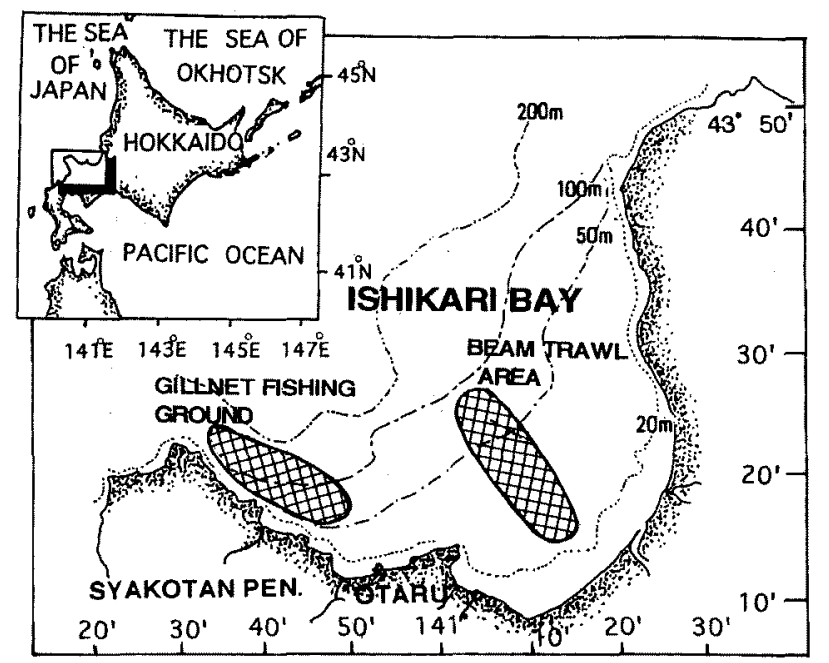

Fig. 1. Map showing sampling area and contours of depth $(\mathrm{m})$ in Ishikari Bay, Hokkaido.

The otoliths of 0 -age flounder could be read without polishing. However, annuli on the otoliths of 1-year-old and older flounder were not clear without polishing. Prior to processing, the otoliths were held in distilled water for 24 hours. The convex side of the otolith was polished with fine sandpaper ( $\# 600-\# 1,000$ grit) until the focus became clearly visible. The otoliths were placed on glass slides and immersed in salad oil. Counts of annulus and otolith measurements were made under a binocular microscope at $\times 10$ magnification using reflected light.

There is a remarkable difference in the position of the fo- 
Table 1 List of samples analyzed in this study

\begin{tabular}{|c|c|c|c|c|c|c|c|c|}
\hline \multirow{2}{*}{\multicolumn{2}{|c|}{ Sampling date }} & \multirow{3}{*}{$\frac{\text { Sampling gear }}{\text { beam trawl }}$} & \multicolumn{6}{|c|}{ Number of individuals } \\
\hline & & & \multicolumn{2}{|c|}{ Male } & \multicolumn{2}{|c|}{ Female } & \multicolumn{2}{|c|}{ total } \\
\hline 24-26 Sep. & 1991 & & & & & & 11 & \\
\hline 11 Nov. & 1991 & beam trawl & & & & & 75 & \\
\hline $24 \mathrm{Feb}$ & 1992 & beam trawl & & & & & 107 & \\
\hline $10 \mathrm{Mar}$. & 1992 & bottom gill net & 48 & (37) & 89 & (74) & 137 & (111) \\
\hline 28 Apr. & 1992 & bottom gill net & 22 & (22) & 65 & (54) & 87 & (76) \\
\hline 11 May & 1992 & bottom gill net & 72 & (58) & 59 & (49) & 131 & $(107)$ \\
\hline 25 May & 1992 & beam trawl & 43 & (43) & 43 & (43) & 86 & (86) \\
\hline 24 Jun. & 1992 & bottom gill net & 33 & (23) & 93 & (83) & 126 & (106) \\
\hline $6 \mathrm{Jul}$ & 1992 & bottom gill net & 34 & (31) & 75 & $(70)$ & 109 & (101) \\
\hline $14 \mathrm{Jul}$. & 1992 & beam trawl & 72 & (61) & 37 & $(30)$ & 109 & (91) \\
\hline 12 Aug. & 1992 & bottom gill net & 131 & (41) & 144 & $(65)$ & 275 & $(106)$ \\
\hline 18 Sep. & 1992 & beam trawl & 13 & (11) & 10 & (7) & 23 & (18) \\
\hline 20 Oct. & 1992 & bottom gill net & 5 & (4) & 87 & $(48)$ & 92 & (52) \\
\hline 21 Nov. & 1992 & beam trawl & 46 & (45) & 29 & (29) & 75 & (74) \\
\hline 10Dec. & 1992 & bottom gill net & 63 & (41) & 121 & $(80)$ & 184 & (121) \\
\hline 20 May & 1993 & beam trawl & & & & & 77 & \\
\hline $27 \mathrm{Jul}$. & 1993 & beam trawl & & & & & 9 & \\
\hline Total & & & 582 & $(417)$ & 852 & (632) & 1,713 ( & $1,049)$ \\
\hline
\end{tabular}

Numbers in parentheses indicates number of individuals used for otolith measurements.

cus $^{7-12)}$ between the ocular side and the blind side of Pleuronectid fish otoliths. This fact also applied to the pointhead flounder used in the present study. Since otolith growth is faster on the axis of the ocular side of the body, ${ }^{10)}$ the ocular side otoliths can be used for reading, especially for the older fish. For this reason, they were used for the growth analysis of Pleuronectes herzensteini $i^{10,13)}$ and H. dubius. ${ }^{12)}$ Therefore, the ocular side otoliths were used for age determination and growth analysis in the present paper. Distances from the focus to the outer margin of each translucent zone $\left(r_{n}\right)$ and the radius of the otolith (R) were measured to the nearest $0.05 \mathrm{~mm}$ along the longest axis from the focus to the anterior edge of the otolith (Fig, 2).

The regression method and Lee (Fraser-Lee)'s method ${ }^{14)}$ were used to estimate the back-calculated length. This regression method estimates the standard length (SL) at some previous time of annulus formation (n) by substituting the measured size of the otolith (r) at the time of annulus formation ( $n$ ) into a fish length-otolith length regression derived from samples by sex,

$$
\mathrm{SL}_{\mathrm{n}}=\mathrm{br}_{\mathrm{n}}+\mathrm{d}
$$

where $b$ and $d$ are the slope and intercept of the regression, respectively. Lee's procedure is described by the following equation:

$$
\mathrm{SL}_{\mathrm{n}}=\mathrm{d}+\left(\mathrm{SL}_{\mathrm{c}}-\mathrm{d}\right) \times\left(\mathrm{r}_{\mathrm{n}} / \mathrm{R}\right)
$$

where $\mathrm{SL}_{c}$ is the standard length at capture.

Growth was assumed to conform to the von Bertalanffy growth function (VBGF), which was calculated using Ishizuka's computer program. ${ }^{15)}$

\section{Results}

\section{Period of Annulus Formation}

Translucent zones and opaque zones were formed alter-

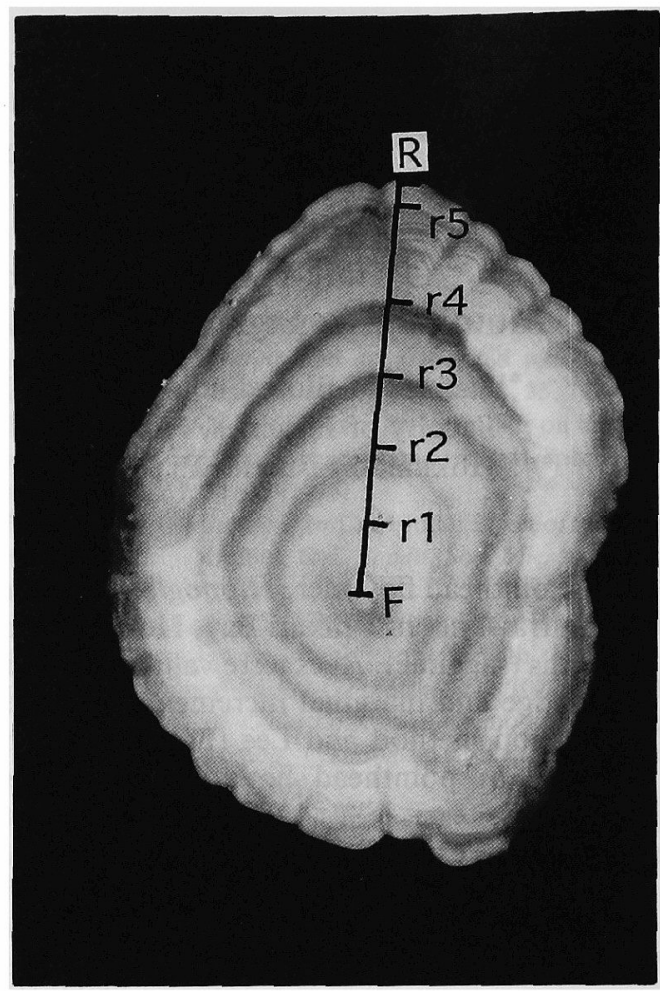

Fig. 2. Ocular side otolith of $H$. pinetorum with five annuli (male, 190 mm SL) collected on 11 May, 1992.

$F$, Focus; $R$, otolith radius; $r_{1}-r_{5}$, annual ring radii.

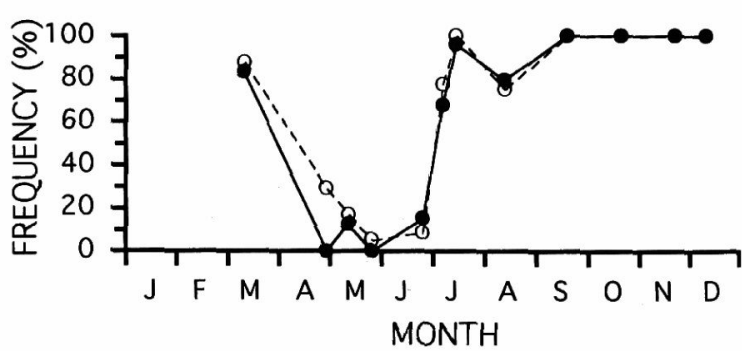

Fig. 3. Monthly changes in percentage of occurrences of otoliths with translucent edges for males (solid circles) and for females (open circles) $H$. pinetorum .

Samples were collected with commercial gillnet and an experimental beam trawl net from March to December 1992.

nately on the otoliths. In order to clarify the period of annulus formation, monthly changes in the percentage occurrence of otoliths with a translucent edge (Fig. 3) were examined.

All fish otoliths had a translucent edge between September and December. The percentage occurrence of otoliths with a translucent edge began to decrease in March, and minimum values for both male $(0 \%)$ and female $(5.4 \%)$ were found in May, respectively. The values for both sexes increased in July. These results show that the outer translucent margin of the otoliths for both sexes is formed chiefly between March and April. No significant differences in percentage occurrence of translucent edges between sexes was observed except in April (Fisher's exact probability test, $p<0.01)$. 


\section{Growth Pattern of Otoliths}

In order to elucidate the growth pattern of otoliths, monthly changes in the average marginal increments of otoliths (MI) were examined on the basis of 827 specimens possessing 1-10 ring marks:

$$
M I=\left(R-r_{n}\right) /\left(r_{n}-r_{n-1}\right)
$$

where $R$ is the otolith radius ( $\mathrm{mm}$ ) and $r_{n}$ is the distance $(\mathrm{mm})$ between the focus and outer margin of the last translucent zone. Minimum values of marginal increment for both sexes were found in March (Fig. 4). Marginal increments then increased rapidly from May to August, reaching a maximum value between September and December.

\section{Standard length-Otolith Radius Relationship and Back- Calculated Length}

Plots of the relationships between otolith radius ( $R$ in $\mathrm{mm}$ ) and standard length (SL in $\mathrm{mm}$ ) are shown in Fig. 5 . Least-square equations for both sexes are:

male: $S L=44.07 R-0.39 \quad\left(n=417, r^{2}=0.949\right)$

Female: $\quad \mathrm{SL}=46.42 \mathrm{R}-2.11 \quad\left(\mathrm{n}=632, \mathrm{r}^{2}=0.941\right)$

The residuals and slope of the regression lines were significantly different between sexes (ANCOVA, residuals:
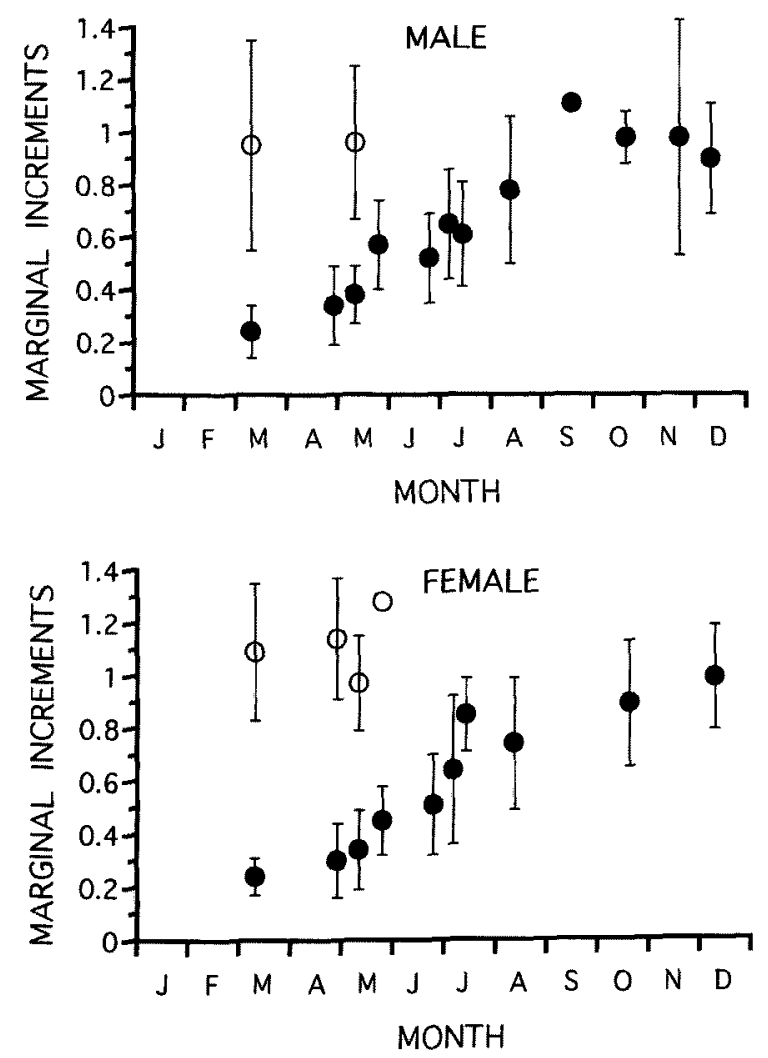

Fig. 4. Monthly changes in marginal increment of otoliths of $H$. pinetorum collected by commercial gillnet and experimental beam trawl net from March to December 1992.

Vertical bars indicate standard deviations. Open circles indicate the mean marginal increments of otoliths which do not have new opaque zones from March through May.
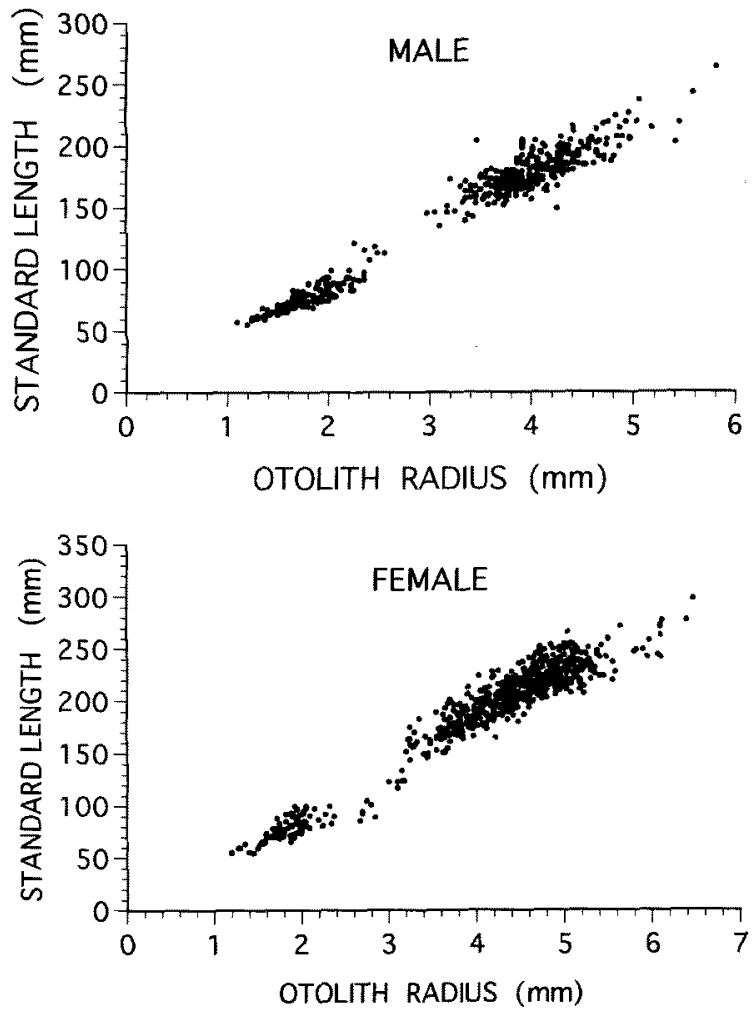

Fig. 5. Relationships between otolith radius and standard lengths of $\boldsymbol{H}$. pinetorum for males and females.

$p<0.01$; slope; $p \ll 0.01)$. The mean radii of each successive otolith annulus at the time of annulus formation are shown in Table 2. Lee's phenomenon was found in $r_{1}$ and $r_{2}$ for both sexes but a clear Lee's or reverse-Lee's phenomenon was not found in $r_{3}-r_{9}$ for either sex. No significant differences between sexes were seen in the mean values of $r_{1}-r_{3}$, while the mean values of $r_{4}-r_{8}$ of females were larger than those of males ( $t$-test, $p<0.01$ ). The mean standard lengths at the time of the $\mathrm{n}$-th annulus formation $\left(\mathrm{SL}_{\mathrm{n}}\right)$ were back-calculated from each mean radius by equations (3) and (4) and Lee's method (Table 3). The differences in standard lengths at the time of each annulus formation obtained by these two methods were similar.

There were significant differences (t-test, $\mathrm{SL}_{2}: p<0.05$; others: $p<0.01$ ) in mean standard length at the time of annulus formation between sexes except for $\mathrm{SL}_{1}$.

\section{Growth}

The major spawning season of pointhead flounder is from June to July in Ishikari Bay. ${ }^{* 4}$ However, the annuli were formed chiefly between March and April, three or four months before the spawning season. Thus, VBGF curves were computed using back-calculated length and age $(t-0.3)$ by Ishizuka's program. ${ }^{15)}$ The growth curves described by this program were as follows: Regression method:

Male: $\quad L_{t}=251.9\left(1-\exp ^{-0.261(t-0.142)}\right)$

Female: $L_{t}=315.1\left(1-\exp ^{-0.219(t-0.200)}\right)$

${ }^{*} 4$ T. Tanaka, Y. Hinata, M. Yamamoto, T. Fukui, H. Kitahama, and K. Hayashi: Sohachi. Showa 36-40 nendo Report of Hokkaido coastal fisheries research and fisheries business economics experiments 
Table 2 Mean ring radii ( $\pm \mathrm{SD}$ ) for each ring group of $H$. pinetorum

\begin{tabular}{|c|c|c|c|c|c|c|c|c|c|c|c|}
\hline \multirow{2}{*}{$\begin{array}{l}\text { Ring } \\
\text { groups }\end{array}$} & \multirow[b]{2}{*}{$\mathrm{N}$} & \multicolumn{10}{|c|}{ Ring radii (mm) } \\
\hline & & $r_{1}$ & $\mathrm{r}_{2}$ & $I_{3}$ & $r_{4}$ & $r_{s}$ & $T_{6}$ & $I_{7}$ & $r_{8}$ & $r_{9}$ & $r_{10}$ \\
\hline \multicolumn{12}{|l|}{ Male } \\
\hline 1 & 135 & $0.82 \pm 0.15$ & & & & & & & & & \\
\hline 2 & 18 & $0.87 \pm 0.16$ & $2.03 \pm 0.29$ & & & & & & & & \\
\hline 3 & 127 & $0.82 \pm 0.18$ & $2.05 \pm 0.25$ & $3.09 \pm 0.26$ & & & & & & & \\
\hline 4 & 64 & $0.73 \pm 0.15$ & $1.72 \pm 0.27$ & $2.73 \pm 0.34$ & $3.60 \pm 0.36$ & & & & & & \\
\hline 5 & 57 & $0.70 \pm 0.18$ & $1.62 \pm 0.30$ & $2.56 \pm 0.36$ & $3.44 \pm 0.37$ & $4.08 \pm 0.33$ & & & & & \\
\hline 6 & 7 & $0.71 \pm 0.13$ & $1.72 \pm 0.12$ & $2.82 \pm 0.24$ & $3.63 \pm 0.20$ & $4.19 \pm 0.19$ & $4.56 \pm 0.23$ & & & & \\
\hline 7 & 3 & $0.60 \pm 0.07$ & $1.57 \pm 0.41$ & $2.53 \pm 0.53$ & $3.28 \pm 0.48$ & $3.92 \pm 0.35$ & $4.27 \pm 0.38$ & $4.51 \pm 0.31$ & & & \\
\hline 8 & 3 & $0.70 \pm 0.07$ & $1.63 \pm 0.20$ & $2.56 \pm 0.23$ & $3.18 \pm 0.20$ & $3.66 \pm 0.09$ & $4.09 \pm 0.07$ & $4.42 \pm 0.11$ & $4.69 \pm 0.13$ & & \\
\hline 9 & 2 & $0.58 \pm 0.04$ & $1.68 \pm 0.18$ & $2.76 \pm 0.05$ & $3.41 \pm 0.30$ & $3.93 \pm 0.39$ & $4.34 \pm 0.55$ & $4.69 \pm 0.58$ & $4.98 \pm 0.57$ & $5.23 \pm 0.67$ & \\
\hline 10 & 1 & 0.45 & 1.03 & 2.88 & 3.53 & 3.90 & 4.30 & 4.60 & 4.95 & 5.10 & 5.35 \\
\hline $\begin{array}{l}\text { weighted } \\
\text { Mean }\end{array}$ & 417 & $0.78 \pm 0.17$ & $1.86 \pm 0.33$ & $2.86 \pm 0.37$ & $3.51 \pm 0.36$ & $4.06 \pm 0.33$ & $4.37 \pm 0.31$ & $4.53 \pm 0.29$ & $4.83 \pm 0.31$ & $5.18 \pm 0.48$ & 5.35 \\
\hline \multicolumn{12}{|l|}{ Female } \\
\hline 1 & 87 & $0.85 \pm 0.17$ & & & & & & & & & \\
\hline 2 & 23 & $0.89 \pm 0.17$ & $2.15 \pm 0.28$ & & & & & & & & \\
\hline 3 & 176 & $0.84 \pm 0.20$ & $2.09 \pm 0.32$ & $3.17 \pm 0.32$ & & & & & & & \\
\hline 4 & 170 & $0.75 \pm 0.16$ & $1.83 \pm 0.30$ & $2.85 \pm 0.37$ & $3.88 \pm 0.40$ & & & & & & \\
\hline 5 & 157 & $0.74 \pm 0.14$ & $1.66 \pm 0.29$ & $2.58 \pm 0.34$ & $3.55 \pm 0.32$ & $4.43 \pm 0.34$ & & & & & \\
\hline 6 & 10 & $0.75 \pm 0.19$ & $1.69 \pm 0.30$ & $2.76 \pm 0.42$ & $3.57 \pm 0.52$ & $4.37 \pm 0.53$ & $5.01 \pm 0.54$ & & & & \\
\hline 7 & 1 & 0.30 & 1.05 & 1.90 & 3.00 & 3.75 & 4.30 & 5.65 & & & \\
\hline 8 & 1 & 0.50 & 1.03 & 1.83 & 2.73 & 3.40 & 3.88 & 4.78 & 5.08 & & \\
\hline 9 & 5 & $0.73 \pm 0.19$ & $1.60 \pm 0.23$ & $2.54 \pm 0.20$ & $3.40 \pm 0.19$ & $4.00 \pm 0.20$ & $4.62 \pm 0.18$ & $5.16 \pm 0.24$ & $5.54 \pm 0.18$ & $5.86 \pm 0.14$ & \\
\hline 10 & 2 & $0.78 \pm 0.18$ & $1.95 \pm 0.46$ & $2.98 \pm 0.32$ & $3.79 \pm 0.58$ & $4.35 \pm 0.53$ & $4.78 \pm 0.46$ & $5.06 \pm 0.51$ & $5.39 \pm 0.41$ & $5.76 \pm 0.30$ & $5.99 \pm 0.27$ \\
\hline $\begin{array}{l}\text { weighted } \\
\text { Mean }\end{array}$ & 632 & $0.79 \pm 0.18$ & $1.87 \pm 0.36$ & $2.87 \pm 0.42$ & $3.71 \pm 0.41$ & $4.41 \pm 0.37$ & $4.78 \pm 0.51$ & $5.15 \pm 0.34$ & $5.44 \pm 0.26$ & $5.83 \pm 0.17$ & $5.99 \pm 0.27$ \\
\hline
\end{tabular}

N: number of otoliths used.

Table 3 Mean back-calculated standard length $(\mathrm{mm})$ at the time of each annulus formation by Regression method and Lee's method

$$
\begin{array}{llllllllll}
\mathrm{SL}_{1} & \mathrm{SL}_{2} & \mathrm{SL}_{3} & \mathrm{SL}_{4} & \mathrm{SL}_{5} & \mathrm{SL}_{6} & \mathrm{SL}_{7} & \mathrm{SL}_{8} & \mathrm{SL}_{9} & \mathrm{SL}_{10}
\end{array}
$$

\section{Regeression}

Male

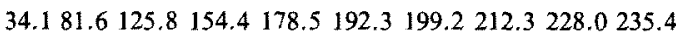

Female $\quad 34.684 .7131 .1170 .1202 .4219 .9236 .8250 .6268 .6275 .8$

Lee

Male $\quad 34.082 .6127 .0152 .9176 .7191 .3202 .6215 .5229 .4231 .3$

Female $\quad 34.785 .7132 .4171 .6204 .9224 .9243 .0258 .0275 .0286 .8$

Lee's method:

Male: $\quad L_{t}=251.6\left(1-\exp ^{-0.263(t-0.142)}\right)$

Female: $\quad L_{t}=333.0\left(1-\exp ^{-0.204(t-0.186)}\right)$

where $L_{t}$ is the standard length $(\mathrm{mm})$ at estimated age $t$ (years).

Theoretical lengths for males estimated by the two backcalculated methods agreed very well but those for females were slightly different beyond 6-7 years (Fig. 6).

\section{Growth of the 1991 Year Class}

Post-settlement juveniles of the 1991 year class were not captured during the experimental beam trawl surveys in June and July 1991. The temporal growth patterns of the 1991 year class collected from September 1991 to July 1993 are shown in Fig. 7. Eleven juveniles of the 1991 year class ranging from 16 to $33.6 \mathrm{~mm}$ SL were collected by beam trawl in September 1991. In November 1991, the average

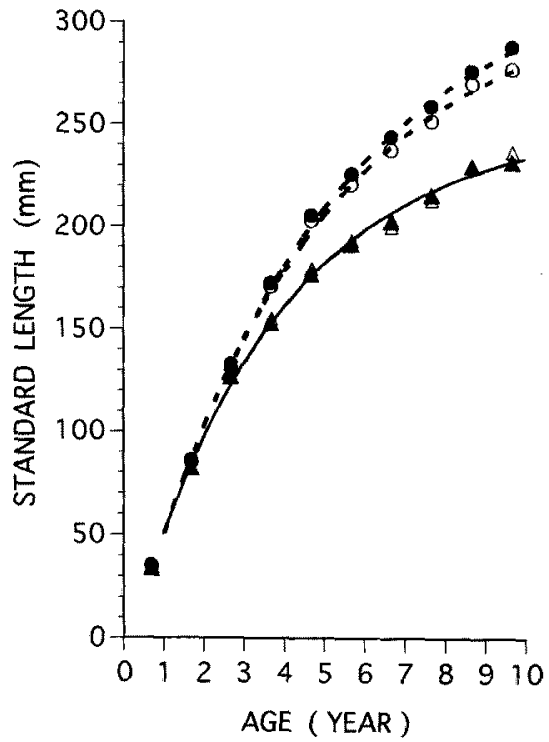

Fig. 6. von Bertalanffy growth curves for $H$. pinetorum for males (solid lines) and females (dashed lines).

The plots represent back-calculated standard length; open triangles: males by regression method; closed triangles: males by Lee's method; open circles: females by regression method; closed circles: females by Lee's method.

standard length of the 1991 year class was $38.6 \mathrm{~mm}$ (SD $5.7 \mathrm{~mm}$ ), which was almost the same size as back-calculated $\mathrm{SL}_{1}$. The average standard length in February 1992 


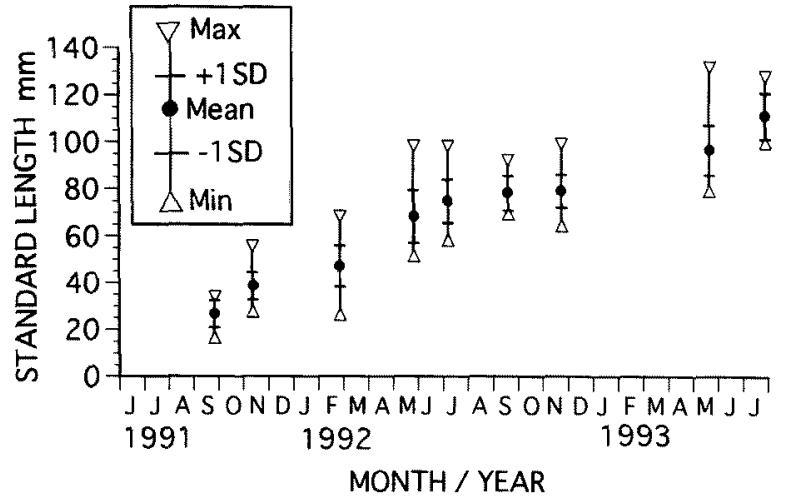

Fig. 7. Monthiy change in standard length of the 1991 year class $H$. pinetorum.

$(47.1 \mathrm{~mm})$ was slightly smaller than the theoretical standard length of 1-year-old fish. Growth rates from February to July were higher (c.a. $5.6 \mathrm{~mm} / \mathrm{month}$ ) than from July to November (c.a. $1.1 \mathrm{~mm} / \mathrm{month}$ ). The mean standard length in May 1993 was $97.0 \mathrm{~mm}$ and it was almost equal to the theoretical length of 2-year-old fish.

\section{Discussion}

All growth back-calculation procedures are based on the proportionality between fish length and some measure of otolith size. ${ }^{14)}$ Regression methods are commonly used for back-calculation. ${ }^{10-13,16-19)}$ Regression-based back-calculation assumes no deviation from the overall regression. However, the otolith radius varied in specimens of the same length. In order to remove the variation of ring radii, $\mathrm{Mio}^{20)}$ proposed that each radius be standardized by the following equation:

$$
r_{n}^{\prime}=\left(R^{\prime} / R\right) \times r_{n}
$$

where $r_{n}^{\prime}$ is the standardized ring radius at the time of $n$-th ring formation and $R^{\prime}$ is an estimate derived from SL at capture of each specimen in the R-SL regression. In contrast, Lee's method ${ }^{14)}$ assumes that individual SL-R deviations are maintained proportionally throughout the backcalculation. Lee's formula has been proposed as the most suitable equation for deriving back-calculated fish lengths using scales. ${ }^{14)}$ In the present study, although small differences in mean back-calculated lengths were found between the two methods, back-calculated lengths were very similar at most estimated ages. Although it is impossible to estimate an individual growth trajectory by using the regression method, it may be appropriate to use the mean backcalculated length in this study.

For the 1991 year class, the observed mean length of the fish collected by the experimental beam trawl net in late February 1992 was similar to the theoretical length predicted by VBGF at 1-year-old, and that in middle May 1993 agreed very well with the theoretical length at 2 -year-old. The mean observed lengths of the 3-6 year-old fish collected by commercial gill nets in May 1992 were larger than the theoretical lengths for both males and females. However, the difference between the observed and theoreti-
Table 4 Mean standard length ( $\mathrm{mm}$ ) at each age of $H$. pinetorum calculated by von Bertalanffy Growth Function (Reg.: back-calculation by Regeression method; Lee: back-calculation by Lee's method) and those in the commercial landing in May $1992(\mathrm{Ob}$ served: mean $\pm \mathrm{SD}$ )

\begin{tabular}{|c|c|c|c|c|c|c|}
\hline \multirow{2}{*}{ Age } & \multicolumn{3}{|c|}{ Male } & \multicolumn{3}{|c|}{ Female } \\
\hline & Reg.* & Lee* & Observed $^{*}$ & Reg.* & $\mathrm{Lee}^{*}$ & Observed* \\
\hline 3 & 132.5 & 132.8 & $160.6 \pm 7.2$ & 144.3 & 145.5 & $170.7 \pm 8.1$ \\
\hline 4 & 160.0 & 160.3 & $168.7 \pm 5.3$ & 177.9 & 180.1 & $193.9 \pm 11.5$ \\
\hline 5 & 181.1 & 181.4 & $184.7 \pm 12.3$ & 204.8 & 208.3 & $220.7+13.9$ \\
\hline 6 & 197.4 & 197.6 & $200.8 \pm 17.3$ & 226.5 & 231.4 & \\
\hline
\end{tabular}

* Reg. and Lee: collected by Beam Trawl net. Observed: collected by Gill nets4.

cal mean lengths became smaller with increasing age (Table 4). The majority of pointhead flounder in the commercial landings ranged from 190 to $220 \mathrm{~mm}$ SL in Ishikari Bay. ${ }^{* 5}$ Therefore, it is clear that the difference between the observed and theoretical mean lengths is closely associated with the mesh selectivity of gill nets.

The asymptotic maximum standard lengths were estimated to be $251.9 \mathrm{~mm}$ (regression) and $251.6 \mathrm{~mm}$ (Lee) for males and $315.1 \mathrm{~mm}$ (regression) and $333.0 \mathrm{~mm}$ (Lee) for females, while the observed maximum lengths of males and females were $262 \mathrm{~mm}$ and $316 \mathrm{~mm}$, respectively. Judging from the above results, it seems reasonable to suppose that the theoretical standard length indicates the approximate actual length at each age except for age 1 . The time of opaque zone formation of 0 -age fish appears to be earlier than that of other ages.

Previous studies on the growth of this species were also made in south-western Japan Sea ${ }^{21-23)}$ and Hachinohe, Pacific coast of northern Honshu Island.9) In the Hachinohe region, the relationship between the time of annulus formation and the spawning season was not clear. However, the time of annulus formation was related to the spawning season in the southwestern Japan Sea, ${ }^{21-23)}$ so we compared the growth data from the southwestern Japan $\mathrm{Sea}^{23)}$ with our data. SL values of our data were converted to total length (TL) using the following equation:

$$
\mathrm{TL}=1.19 \mathrm{SL}+2.83 \quad\left(\mathrm{n}=927, \mathrm{r}^{2}=0.996\right)
$$

The parameters of VBGF of pointhead flounder from the southwestern Japan Sea were recalculated by Ishizuka's program from the age-length data presented elsewhere. ${ }^{23)}$ Pointhead flounder in the southwestern Japan Sea are larger than those in Ishikari Bay except for 1-year-old fish (Table 5). The difference of growth between the above two areas is caused mainly by differences in growth rates $(\mathrm{mm} /$ year) of 1- and 2-year-old groups (Table 5).

In the southwestern Japan Sea, large differences (50-60 $\mathrm{mm}$ ) in mean body length of 1- and 2-year-old fish between the west fishery ground and the east fishery ground were found..$^{21,24)}$ Watanabe ${ }^{24)}$ suggested that the differences might be caused by not only geographical differences in the food amount for 1- and 2-year-old fish and the fish density but also a distributional relation between flathead flounder and other fishes. 
Table 5 Mean total length calculated by von Beratlanffy Growth Function (VBGF) of $H$. pinetorum from South-western Japan Sea (SW Jap. Sea) and Ishikari Bay. Reg.

\begin{tabular}{|c|c|c|c|c|c|c|c|c|c|c|c|c|}
\hline & \multicolumn{6}{|c|}{ Total Length calculated by VBFG mm } & \multicolumn{6}{|c|}{ Growth rates (mm/year) } \\
\hline & \multicolumn{3}{|c|}{ Male } & \multicolumn{3}{|c|}{ Female } & \multicolumn{3}{|c|}{ Male } & \multicolumn{3}{|c|}{ Female } \\
\hline & \multirow{2}{*}{$\begin{array}{c}\text { SW Jap. } \\
\text { Sea }\end{array}$} & \multicolumn{2}{|c|}{ Ishikari Bay } & \multirow{2}{*}{$\begin{array}{c}\text { SW Jap. } \\
\text { Sea }\end{array}$} & \multicolumn{2}{|c|}{ Ishikari Bay } & \multirow{2}{*}{$\begin{array}{c}\text { SW Jap. } \\
\text { Sea }\end{array}$} & \multicolumn{2}{|c|}{ Ishikari Bay } & \multirow{2}{*}{$\begin{array}{c}\text { SW Jap. } \\
\text { Sea }\end{array}$} & \multicolumn{2}{|c|}{ Ishikari Bay } \\
\hline & & Reg. & Lee & & Reg. & Lee & & Reg. & Lee & & Reg. & Lee \\
\hline 2 & 135.5 & 118.1 & 118.4 & 141.0 & 124.9 & 125.4 & 79.5 & 55.1 & 55.2 & 87.6 & 61.9 & 61.9 \\
\hline 3 & 187.5 & 160.5 & 160.9 & 205.1 & 174.5 & 176.0 & 52.0 & 42.4 & 42.5 & 64.1 & 49.6 & 50.6 \\
\hline 4 & 221.4 & 193.2 & 193.6 & 252.2 & 214.5 & 217.1 & 33.9 & 32.7 & 32.7 & 47.1 & 40.1 & 41.2 \\
\hline 5 & 243.6 & 218.3 & 218.7 & 286.7 & 246.5 & 250.7 & 22.2 & 25.1 & 25.1 & 34.5 & 32.0 & 33.6 \\
\hline 6 & 258.1 & 237.7 & 238.0 & 312.0 & 272.4 & 278.2 & 14.5 & 19.4 & 19.4 & 25.3 & 25.8 & 27.5 \\
\hline 7 & 267.6 & 252.7 & 252.8 & 330.6 & 293.1 & 300.4 & 9.5 & 15.0 & 15.0 & 18.6 & 20.7 & 22.3 \\
\hline 8 & 273.7 & 264.2 & 264.3 & 344.1 & 309.7 & 318.7 & 6.1 & 11.4 & 11.4 & 13.5 & 16.7 & 18.2 \\
\hline
\end{tabular}

Back-calculation by Regression method; Lee: back-calculation by Lee's method. Parameters of VBGF for $H$. pinetorum from south-western Japan Sea were recalculated as follows: $\mathrm{TL}_{\mathrm{t}}=285.4\left(1-\exp ^{-0.426(t-0.4877}\right)$ for male, $\mathrm{TL}_{\mathrm{t}}=381.5\left(1-\exp ^{-0.310(\mathrm{t}-0.514)}\right)$ for female based on the data of Done. ${ }^{23)} \mathrm{Maximum}$ age in the study was 6 years old (one specimen) for male and 7 years old (two specimens) for female.

The 1- and 2-year-old groups inhabit the shallow waters in Ishikari Bay while the main habitat of fish aged 3 years and older is in the deep area out beyond Ishikari Bay. ${ }^{25)}$ To confirm the cause of the geographical variation in growth of pointhead flounder, studies on fish biomass, distribution and feeding habits of 1 - and 2-year-old fish combined with biological, physical and chemical environment factors are required.

Acknowledgments The authors would like to thank the crew of the R/ V Oyashio-Maru, Hokkaido Fisheries Experimental Station, for their help with data collection. Thanks are also due to K. Ishino and T. Fujioka, Hokkaido Fisheries Experimental Station, for collecting the references and M. Canino, National Marine Fisheries Service NOAA, for reading the draft and making a number of helpful suggestions.

\section{References}

1) T. Tanaka and $\mathrm{H}$. Yoshida: On the tagging experiment of Sohachi (Cleisthenes pinetorum herzensteini (SCHMIDT)) in 1959. J. Hokkaido Fish. expl. Stn., 17, 117-122 (1959) (in Japanese).

2) T. Tanaka, Y. Hinata, Y. Yamashita, and S. Ohara: The life of the sohachi flounder in the coastal waters off Rumoi. J. Hokkaido Fish. expl. Stn., 19, 517-530 (1962) (in Japanese).

3) T. Tanaka and Y. Hinata: The life of the sohachi flounder in the coastal waters off Rumoi again-Especially pre-spawning period and spawning period. J. Hokkaido Fish. expl. Stn., 21, 9-25 (1962) (in Japanese).

4) O. Tominaga and Y. Watanabe: Movement of tagged pointhead flounder Hippoglossoides pinetomum off Tomari, Shiribeshi, Hokkaido. Sci. Rep. Hokkaido Fish. expl. Stn., 44, 29-31 (1994).

5) S. Hayase and I. Hamai: Studies on feeding habits of three flatfishes, Cleisthenes pinetorum herzensteini (Schmidt), Hippoglossoides dubius (Schmidt) and Glyptocephalus stelleri (Schmidt). Bull. Fac. Fish. Hokkaido Univ., 25, 82-99 (1974).

6) T. Nagasawa: Planktonic larvae of the pointhead-flounder, Cleisthenes pinetorum herzensteini in the northern Japan Sea. Bull. Japan Sea natn. Fish. Res. Inst., 40, 15-25 (1990) (in Japanese).

7) K. Suzuki: Growth of Kareius bicoloratus (BASILEWSKY) deduced from otolith. Rep. Fac. Fish. Pref. Univ. Mie, 5, 455-468 (1966).

8) K. Suzuki: Age and growth of Limanda yokohamae (GUNTHER) in Ise Bay. Rep. Fac. Fish. Pref. Univ. Mie, 6, 17-27 (1967).
9) Y. Ishito: Age and growth of the three flounder species, "soHACHI", roundnose and "MIGIGAREI" flounders, in the fishing area off Hachinohe. Bull. Tohoku Natl. Fish. Res. Inst., 24, 73-80 (1964) (in Japanese).

10) K. Wada: Studies on the population biology of the flatfish, Limanda herzensteini JORDAN et SNYDER in Niigata region. Bull. Japan Sea reg. Fish. Res. Lab., 22, 31-43 (1990) (in Japanese).

11) Y. Masaki, H. Itoh, T. Tokai, and Y. Yamaguchi: Age and growth of Finespotted flounders in Suo-nada area. Nippon Suisan Gakkaishi, 51, 1963-1970 (1985) (in Japanese).

12) T. Nakatani, H. Koizumi, S. Yokoyama, T. Maeda, T. Takahashi, and $\mathrm{H}$. Matsushima: Age and growth of Pleuronectid flounder Hip. poglossoides dubius in Funka Bay, Hokkaido. Nippon Suisan Gakkaishi, 56, 893-901 (1990) (in Japanese).

13) S. Nishiuchi: The growth of the flatfish, Limanda herzensteini JORDAN et SNYDER, in the Esashi area of the northern coast of Hokkaido. J. Hokkaido Fish. expl. Stn., 41, 107-118 (1984) (in Japanese).

14) K. D. Carlander: Caution on the use of the regression method of back-calculating lengths from scale measurements. Fisheries, 6, 2-4 (1981).

15) Y. Ishizuka: Estimation of von Bertalanffy growth curve by nonlinear least square method, in "Pasokon ni yoru Sigenkaiseki Program Syu” (ed. Suuritoukei-bu Tokaiku Suisan Kenkyusyo), 1-15 (1988) (in Japanese).

16) Y. Masaki, H. Itoh, T. Tokai, and Y. Yamaguchi: Age and growth of Japanese flounder in Suo-nada of Seto Inland Sea. Nippon Suisan Gakkaishi, 52, 423-433 (1986) (in Japanese).

17) Y. Masaki, H. Itoh, T. Tokai, and Y. Yamaguchi: Age and growth of stone flounder in Suo-nada of Seto Inland Sea. Nippon Suisan Gakkaishi, 52, 435-445 (1986) (in Japanese).

18) S. Kimura, Y. Nakayama, and K. Mori: Age and growth of the Iabrid fish Halichoeres poecilopterus in Ago Bay, central Japan. Nippon Suisan Gakkaishi, 58, 811-817 (1992).

19) S. Kimura, Y. Nakayama, and K. Mori: Age and growth of the labrid fish, Pseudolabrus japonicus in Ago Bay and its adjacent water, central Japan. Suisanzoshoku, 42, 339-344 (1994).

20) S. Mio: Studies on population biology of coastal fishes in Kyusyu-1: Biology of Sebastes inermis Cuvier et Valenciennes. Sci. Bull. Fac. Agr. Kyusyu Univ., 18, 419-436 (1961).

21) A. Ouchi: Age and growth the flat fish, Cleisthenes herzenstein (SCHMIDT) by scale measuring. Nissuiken Gyoseki, 1, 27-32 (1954) (in Japanese).

22) T. Watanabe: The population studies of the bottom-fishes in the south-western Japan Sea (1) Age determination, composition and 
survival rate of Cleisthenes herzensteini (SCHMIDT). Nissuiken Gyoseki, 1, 65-81 (1954) (in Japanese).

23) J. Done: Growth of pointhead flounder in the south-western Japan Sea. Seikai Block Sokouo Chosa Kenkyu Kaiho, 4, 29-41 (1993) (in Japanese).

24) T. Watanabe: The population studies of the bottom-fishes in the south-western Japan Sea (2) Cline distribution observed on the growth of the plaice, Cleisthenes herzensteini (SCHMIDT). Ann. Rept. Japan Sea reg. Fish. Res. Lab., 4, 181-188 (1958) (in Japanese).

25) O. Tominaga: Distribution of immature pointhead flounder Cleisthenes pineforum herzensteini, in Ishikari Bay, Hokkaido Japan. Bull. Japan Soc. Fish. Oceanogr., 53, 29-33 (1989) (in Japanese). 